Essay

\title{
In Search of a Long-Awaited Consensus on Disciplinary Integration in STEM Education
}

\author{
David Aguilera ${ }^{1, *(\mathbb{D})}$, José Luis Lupiáñez ${ }^{2}$, José Miguel Vílchez-González ${ }^{1}$ (i) \\ and Francisco Javier Perales-Palacios ${ }^{1}$ (D) \\ 1 Department of Science Education, University of Granada, Campus Universitario de Cartuja, s/n, \\ 18071 Granada, Spain; jmvilchez@ugr.es (J.M.V.-G.); fperales@ugr.es (F.J.P.-P.) \\ 2 Department of Mathematics Education, University of Granada, 18071 Granada, Spain; lupi@ugr.es \\ * Correspondence: davidaguilera@ugr.es
}

check for updates

Citation: Aguilera, D.; Lupiáñez, J.L.; Vílchez-González, J.M.;

Perales-Palacios, F.J. In Search of a Long-Awaited Consensus on Disciplinary Integration in STEM Education. Mathematics 2021, 9, 597. https://doi.org/10.3390/math9060597

Academic Editor: Michael Voskoglou

Received: 4 February 2021

Accepted: 8 March 2021

Published: 11 March 2021

Publisher's Note: MDPI stays neutral with regard to jurisdictional claims in published maps and institutional affiliations.

Copyright: (c) 2021 by the authors. Licensee MDPI, Basel, Switzerland. This article is an open access article distributed under the terms and conditions of the Creative Commons Attribution (CC BY) license (https:/ / creativecommons.org/licenses/by/ $4.0 /)$.

\begin{abstract}
The emergence of STEM (Science, Technology, Engineering, and Mathematics) in research and the practice of science, technology, engineering, and mathematics education is today an unquestionable fact at international level. Despite the importance attached to STEM education, there is a lack of synthesized approaches to teaching the interdisciplinarity of STEM. This lack of synthesis can hinder a strong theoretical foundation for STEM education and possible new contributions. The purpose of this position paper is to contribute a theoretical framework for STEM education that enables the unification of criteria regarding disciplinary integration and associated teaching methods. The authors discuss disciplinary integration in STEM activities, the implication of STEM literacy, educational stage, and teaching method, and provide suggestions for future research.
\end{abstract}

Keywords: STEM education; STEM literacy; framework; disciplinary integration; teaching methods

\section{Introduction}

This position paper has the aim of contributing a theoretical framework for STEM (Science, Technology, Engineering, and Mathematics) education that permits the unification of criteria regarding disciplinary integration and associated teaching methods, at least in the educational plane. In our opinion, this objective could help reduce the ambiguity that STEM education maintains today.

The acronym STEM (Science, Technology, Engineering, and Mathematics) was first employed in 2001 by the director of the Education and Humanities division of the National Science Foundation, Judith A. Ramaley, in reference to the curricula of the disciplines involved. Since then it has been gaining importance both at political and educational level, while adopting different meanings depending on the sector we find ourselves in, with three conceptualizations being distinguished [1]: (1) educational; (2) political-social; and (3) personal-alluding to that carried out by each individual. This has led to some authors, such as Bybee [2], classifying STEM as an ambiguous term.

Regarding the educational plane, on which we will focus this essay, Martín-Páez et al. reviewed articles that contained educational experiences associated with the STEM educational approach [3]. Their objective was to respond to the question, "What are we talking about when we talk about STEM education?" This study concluded that there is no consolidated criterion when referring to STEM education, finding works that (1) only focus on one discipline; (2) produce different combinations without coming to integrate the four disciplines involved in the acronym; and (3) integrate the four disciplines into a single didactic experience. Consequently, educators have acquired very different conceptualizations of STEM education [4,5], which seem to bring them to a state of anxiety and insecurity and, in some cases, to reject the implementation of this educational approach in the classroom. 
Having arrived at this point, we must differentiate between those studies that have focused on clarifying what STEM or STEM education is $[1,3,6,7]$, and those that have contributed to its theoretical-practical development through different frameworks or models [8], the latter being a theoretical creation that permits us to understand a reality.

\section{STEM Education}

From a broad perspective, perhaps too broad, Hsu and Fang define STEM education as an educational approach in which the contents of the disciplines involved may be addressed: (1) as a group of isolated ideas (multidisciplinary); or (2) as ideas integrated into the process of real world problem-solving (interdisciplinary and cross-disciplinary) [9].

In our opinion, such open definitions of STEM education may have created the need to add some qualifiers to the term in order to specify its meaning. Thus, there has been a coining of such terms as "integrative STEM education", which refers to the educational approach that integrates the teaching and learning of two or more subjects that comprise the acronym, and/or between one of these and one or more school subjects-arts, humanities, etc. [10], and "integrated STEM education" [11], for which there has been no further clarification beyond the need to integrate various disciplines from the acronym into an educational experience. Wells emphasizes that "integrative STEM education" alludes to a dynamic, student-focused process, whereas "integrated STEM education" suggests a more static teaching-learning process, focused on the teacher [12]-although also orientated towards disciplinary integration.

In any event, and from our perspective, adding the terms "integrative" or "integrated" to STEM education is redundant, as the acronym already alludes to disciplinary integration. STEM education should be defined, according to Martín-Páez et al. [3], as the educational approach that promotes the integration of content (concepts, skills and/or attitudes) originating from science, technology, engineering, and mathematics in the resolution of real-world problems. Furthermore, this definition clearly differentiates between STEM education and previous educational approaches such as STS (Science, Technology, and Society) [13].

In short, if we assume that the conceptualization of STEM education varies according to the sector we find ourselves in —educational, political-social, and individual [1]—we must endeavor, at least in the educational sphere, to ensure agreement on the meaning of this approach. Otherwise, if we promote the term STEM education as being polysemic, even within the same sphere, we could be creating "communication barriers" [4] which, in the end, would only contribute to wrecking an educational approach that has the intention of adapting the teaching-learning process to the social characteristics and needs of the 21st century. It is thus essential to adopt a shared definition between the interested parties who need to develop their work collaboratively [14].

\subsection{Level of Integration of the STEM Disciplines}

At present, various STEM models articulate different ways of integrating the STEM disciplines. These, ordered from lowest to highest level of integration according to Gresnigt et al. [15], are (1) nested, e.g., [16]; (2) multidisciplinary, e.g., [17]; (3) interdisciplinary, e.g., [18,19]; and (4) transdisciplinary, e.g., [20]. In contrast, the reference framework proposed by Kelley and Knowles [21] does not specify anything on this matter. In any event, the frameworks in which the level of disciplinary integration is specified do not offer reasons that justify their decision. In this regard, Pearson has already pointed out that there is little (or no) research on the best way of integrating the STEM disciplines, or on which factors make integration more effective [22].

In line with the aforementioned, we must consider, despite Sanders [23] having identified three degrees of integration for STEM education (multidisciplinary, interdisciplinary, and transdisciplinary), that there is little educational research focused on determining what the best way of integrating the disciplines in STEM education are [22]. The different modes for implanting this educational approach proposed in Table 1 could thus contribute 
a framework that is systemized, with individual factors for each of them, and grounded, following the guidelines offered by Gresnigt et al. [15] on disciplinary integration, capable of supporting empirical study on the impact of the degree of disciplinary integration on the effects generated by STEM education.

Table 1. Levels of integration of the STEM (Science, Technology, Engineering, and Mathematics) disciplines.

\begin{tabular}{|c|c|}
\hline & Descriptions \\
\hline Level 1 & $\begin{array}{l}\text { - Science, Technology, Engineering and Mathematics are incorporated in the } \\
\text { same activity. The links between disciplines and society are made explicit. } \\
\text { Furthermore, each discipline has its own learning goals. One STEM discipline } \\
\text { is dominant over the others (as indicated by the learning goals) } \rightarrow \text { STEM } \\
\text { education (nested). } \\
\text { All STEM disciplines are equally relevant } \rightarrow \text { STEM education } \\
\text { (multidisciplinary). }\end{array}$ \\
\hline Level 2 & $\begin{array}{l}\text { - Science, Technology, Engineering and Mathematics are incorporated in the } \\
\text { same activity. The learning goals transcend the individual disciplines, since } \\
\text { they involve various disciplines. Furthermore, the learning goals are } \\
\text { (predominantly) curriculum oriented } \rightarrow \text { STEM education (interdisciplinary). }\end{array}$ \\
\hline Level 3 & $\begin{array}{l}\text { - Science, Technology, Engineering and Mathematics are incorporated in the } \\
\text { same activity. The learning goals transcend the individual disciplines, since } \\
\text { they involve various disciplines. These focus on the problem, preferably } \\
\text { real-world problem, and they are oriented towards social implications } \rightarrow \text { STEM } \\
\text { education (transdisciplinary). }\end{array}$ \\
\hline
\end{tabular}

\subsection{STEM Literacy, Disciplinary Integration, and Educational Stages}

The three levels of integration proposed (Table 1) could be justified based on the STEM literacy concept. This concept has been defined as "the ability to identify, apply and integrate concepts from science, technology, engineering, and mathematics to understand complex problems and to innovate to solve them" [24]. Thus, Bybee [25] specifies that STEM literacy involves:

- Managing scientific, technological, engineering, and mathematical knowledge to identify problems.

- Acquiring new knowledge, the product of the integration, and applying it to the solving of problems.

- Understanding the characteristic features of science, technology, engineering, and mathematics.

- Recognizing how STEM disciplines shape our material, intellectual, and cultural world.

- Becoming involved in subjects related to science, technology, engineering, and mathematics as committed, active and critical citizens.

At this point, it is easy to infer that (1) implementing the STEM educational approach in the classroom would promote STEM literacy; and (2) according to the STEM literacy implications, it is aligned with transdisciplinary integration. However, we must consider that this ability is not innate, since students are not able to recognize the links between STEM disciplines and, frequently, nor do they appreciate their implications for authentic problems [22]. Therefore, establishing a process to gradually achieve STEM literacy should be the focus of the efforts of STEM researchers and educators.

A plausible explanation for this gradual process may be found in the experience of students (academic and life) and their cognitive development, both aspects usually associated with age. Thus, the decision to adopt the STEM approach should consider the level of STEM literacy in students. Hence, independently of their education stage, we 
should consider their experience with activities based on STEM education and, as a result of the foregoing, their capacity to identify relationships among scientific, technological, engineering, and mathematical contents. Additionally, the complexity of the problematic situations used-considering the difficulty of the contents associated with these and the degree of disciplinary integration-should also guide the implementation of the STEM approach in the classroom (Figure 1).

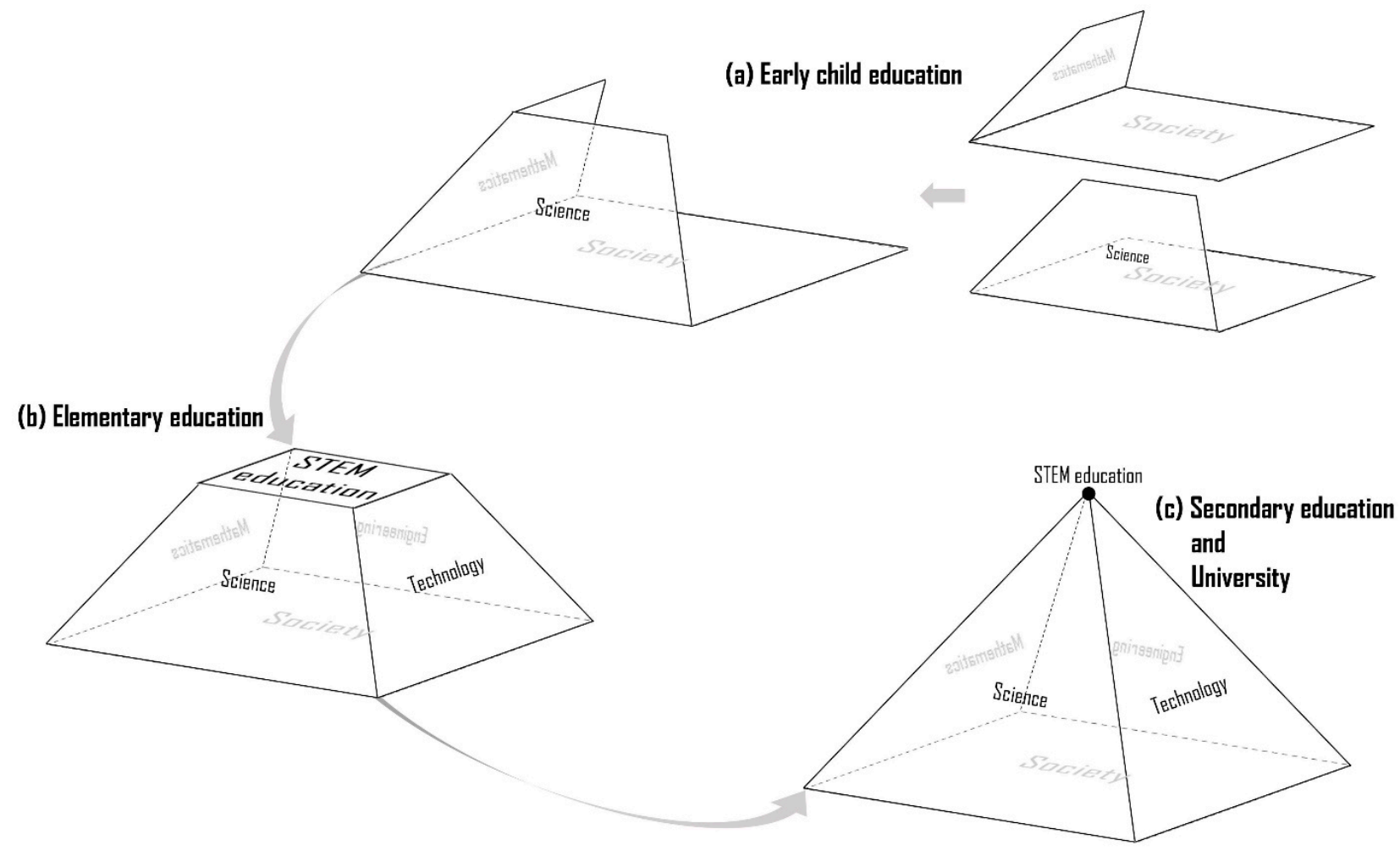

Figure 1. Implementation of the STEM approach in the different educational stages.

From our point of view, in early childhood education it would be more recommendable to choose simple problem situations that make it possible to show students the effect of the STEM disciplines on society (Figure 1a), in a way that the understanding (identification and application) of their social repercussions is the preamble to the implementation of a STEM approach in the educational stages following it. Thus, in order to gradually implement STEM education it would be recommendable to opt for a nested or multidisciplinary degree of integration (Table 1, level 1) in primary education (Figure 1b). Both modes of disciplinary integration are characterized by making the existing connections among the disciplines involved in the task explicit [15], in a way that the development of STEM literacy in students would begin. In this initial stage the teacher is fundamental, as he or she will be responsible for making the connections between the STEM disciplines visible and, in parallel, the possible repercussions they may have on society. In secondary and university education the teacher could adopt a more secondary role, given that students would have certain experience in this educational approach, and the acquisition of STEM literacy would have already started. Therefore, in these educational stages (Figure 1c), it could be possible to opt for a degree of interdisciplinary or transdisciplinary integration (Table 1, levels 2 and 3), which leave the identification of the existing links between the STEM disciplines in the hands of students, along with the integrated application of their knowledge to solve the problematic situations set. 


\subsection{Teaching Methodologies and Disciplinary Integration}

The level of disciplinary integration will be linked, undoubtedly, to the teaching method used and the contents addressed. In this sense, four different methodologies associated with STEM education have been identified: (1) inquiry-based learning [16]; (2) project-based learning [17-19]; (3) problem-based learning [18,20]; and (4) engineering design [21]. In relation to the plurality of didactic strategies, Pearson argued the lack of clarity regarding which of them will be able to contribute to a greater extent in the creation of links between science, technology, engineering, and mathematics [22]. In this regard, the following section takes this premise as central, along with the rest of the defining characteristics of STEM education, to provide a theoretical basis for the teaching method that could be the most suitable.

As we have pointed out, the integration of science, technology, engineering, and mathematics is a basic principle in the STEM approach, in such a way that the teaching method associated with it should participate in the fulfilment of this principle, as well as providing a problematic situation that arises from a specific, preferably real, context.

\subsubsection{Inquiry-Based Learning}

It is a process that, from the identification and analysis of a problem [26], allows one to understand the different way in which scientists carry out their work; evaluate the potential of observations; develop the ability to formulate researchable questions and produce hypotheses; use different types of data to search for patterns and confirm or reject predictions; build and defend models and arguments; consider alternative explanations; achieve a better understanding of the provisional and evolutionary nature of Science; and show the relationship between Science and human activity, and the context and the culture in which it develops and is used [27].

An example of application of this teaching method, within the framework of the STEM approach, is the didactic intervention developed by Toma and Greca [28]. They understand inquiry-based teaching, "as a set of activities that seek to assimilate the learning of science and the processes and strategies that scientists follow to resolve problems in real world situations" (p. 1385), and establish a model based on four phases in which the scientific and engineering domains prevail over the technological and mathematical domains.

[ ... ] in the first phase (inquiry invitation), the teacher proposes an engineeringbased real-world problem that serves as a context to teach science-related content matter. During the second phase students perform a guided inquiry in which they conduct different experiments using scientific practices, technology, and interpret data using mathematics. The third phase consists of an open inquiry during which students should discuss the results obtained in the guided inquiry and propose new research questions necessary to solve the initial problem. The fourth and final phase (inquiry resolution) requires the design or implementation of a solution which could be technological in nature.

(p. 1385) [28]

\subsubsection{Project-Based and Problem-Based Learning}

Both have often been identified as synonymous. Therefore, using the works of Boud and Feletti [29] and Savin-Baden [30] as a basis, we believe it convenient to define both teaching methods by their differences:

- Despite starting out from a problematic situation, project-based learning directs the teaching-learning process towards the production of a report, device or other type of product that represents the solution thereof. Problem-based learning, however, focuses on the analysis of the problem and the knowledge necessary to solve it. So, in problem-based learning the solution of the problem can be part of the process, but the focus is on the management thereof, not on obtaining a clear and delimited solution as occurs in project-based learning. 
- Project-based learning affords the teacher a supervisory role, directing the student production process. In problem-based learning the teacher fulfils the role of facilitator, guiding students in the acquisition of knowledge and discovery of the existing links therein, with the problem and the context.

- Project-based learning tends to be implemented to apply knowledge acquired from theory, that is, to acquire experience. Problem-based learning is used when students have a certain command and experience of the different contents that emerge from the problematic situation, in a way that the aim is to consolidate and expand on the already acquired knowledge.

- Project-based learning can focus on one curricular area or integrate various, which will depend on the desired product. In contrast, problem-based learning assumes that learning will take place in the crossovers among the different disciplines or curricular areas.

Lou et al. [31] and Kim and Chae [32] can exemplify, respectively, the implementation of project-based and problem-based learning within the framework of STEM education. Thus, Lou et al. establish a training process based on five premises: "setting the goal first and then making the plan; carefully designing the guidance problems; evaluating the plan; formulating the professional plan; and managing the process" (p. 2392) [31], which encourage the authors to formulate the objectives to be achieved in each of the STEM domains. Similarly, Kim and Chae establish three phases to solve the problematic issues: (1) context stage; (2) creative design; and (3) emotional touch. This training process focuses on the problem to be solved and attends to disciplinary relationships, difficulties and emotions manifested by the students during the resolution of the problem. This is so much the case that in this didactic intervention the authors present the contents according to the problem they intend to solve, transcending the curricular areas and favoring the adoption of a more holistic position.

\subsubsection{Engineering Design}

It could be defined as a process that starts with the identification of a problem specifying its limitations; it continues establishing those criteria and restrictions that will guide the design; and it ends with a practical solution to the problem [33]. This design process is generally creative, iterative, and open [34].

An example of an application of this teaching strategy within the framework of STEM approach is the didactic intervention developed by Shahali et al. [35]. They consider that engineering design generates an ideal context "to connect science, mathematics and technology into real world scenario to increase students' interest towards STEM" (p. 1190) [35]. Therefore, Engineering provides the educational context and establishes the way to proceed to solve the problem proposed in this educational experience.

The four teaching methodologies, in accordance with the characterization carried out, begin from a problematic situation, and contextualize the teaching-learning process. This makes them all suitable for association with the STEM approach. Notwithstanding, we must focus on the capacity of these teaching methods to integrate the four STEM disciplines. In this regard, we could group them into two types: specific and general.

Specific teaching methodologies would be inquiry-based learning and engineering design, due to their strong connections to science and engineering, respectively. Basing the teaching-learning process on the modus operandi of a specific profession (scientist or engineer) therefore makes it inevitable that the discipline associated with it (science or engineering) plays a more significant role. Therefore, if we thus consider the four ways of integrating the STEM disciplines proposed in Table 1, inquiry-based learning and engineering design would adjust well to a nested level of integration, but it would be difficult for them to reach a multidisciplinary, interdisciplinary, or transdisciplinary integration.

The general teaching methodologies, problem-based learning, and project-based learning, allow for a greater level of integration. We find an example of this in different STEM models. On the one hand, Kim [17] and Tsai et al. [19], who associate project-based learn- 
ing with STEM education, propose a multidisciplinary and interdisciplinary integration, respectively. On the other hand, Basham et al. [18], who appear to assume problem-based learning and project based learning as synonymous, suggest an interdisciplinary integration, whereas Quigley et al. [20] suggest a transdisciplinary integration associated with the implementation of problem-based learning. Therefore, given the capacity of problem-based learning to adopt any type of integration, we consider that this teaching method should be the first option to be associated with the STEM approach. Our position is grounded on the following contributions:

- The majority of real-world problems are interdisciplinary, meaning that the objective of revealing connections and interactions between disciplines is natural. Regardless, in the academic sphere, the degree of disciplinary integration can vary depending on the design of the problem and the orientation of the teacher [36].

- Creativity is the ultimate expression of the resolution of problems and involves new and original transformations of ideas and the creation of new integrating and explanatory principles. As a result, this puts into play our capabilities for interpreting reality beyond the usual codes, establishing unforeseen associations, exploring that which initially appears unpredictable to find innovating and viable responses to the problems we attempt to solve [37].

- The structure of the problem involves students in learning and gives them the responsibility of discovering in some way what is taking place. Moreover, the problem is designed to be sufficiently wide-ranging to make the need for collaboration evident, in a similar way to that which occurs in the real world [38].

- Learning and motivation increase when the study plan is based on relevant, generally real problems [39]. Furthermore, the underlying contents of the problem are very meaningful for students, in such a way that they provide the most effective basis for the long-term retention of information [40].

- The complex problems of the real world often involve ethical dilemmas, to the extent that problem-based learning presents the opportunity to explore the ethical dimensions of any problem [38].

\section{Summary}

From the beginnings of Science Education as a formalized discipline different research currents have arisen, with foundations of a varying nature and emphasis. There can be no doubt that STEM education has become consolidated in practice as one of the currents with a growing influence in the way of conceiving and putting not only science but also technology, engineering, and mathematics education into practice. This development, to a certain extent explosive, has nevertheless not been accompanied by a theoretical foundation with which to design and interpret educational experiences based on the STEM educational approach. This anomalous growth could eventually lead to the STEM movement being considered as just another fad.

Given the above, STEM education should be defined as one that integrates contents (concepts, skills, and/or attitudes) from science, technology, engineering, and mathematics to solve problems [3]. Thus, disciplinary integration, which will depend to a large extent on the contents addressed, could be carried out by combining different tasks-understood as a segment of a (STEM) activity to allow the development and assessment of a disciplinary idea and/or a practice [41] —in a structured sequence according to the links of the different STEM domains. Thus, three levels of disciplinary integration have been established in order to provide a useful framework to design, interpret, and implement activities based on the STEM approach.

The first level considers nested integration, which has been recommended for use when students have a low level of STEM literacy and has been associated with teaching methods such as inquiry-based learning or engineering design, and multidisciplinary integration. Both forms of disciplinary integration are characterized by specifying learning goals for 
each discipline, although in the case of nested integration the importance assigned to each discipline is not balanced.

Interdisciplinary integration would correspond to the second level. This way of combining the STEM domains could be reflected in learning goals that have implications in several subjects. Thus, the last level of integration (transdisciplinary) would imply setting learning goals that transcend the curriculum and STEM disciplines; that is, they are focused on the problem to be solved. Transdisciplinary integration would permit awareness to be raised, in a natural way, of the implications that other areas of knowledge such as Social Sciences or Humanities have in solving real problems. This was already seen by Sanders [10] when offering his view of STEM education, the first known operational definition; he "opened the door" to the consideration of disciplines such as History, Arts, and Philosophy when implementing the STEM approach. In this regard, the second and third levels of disciplinary integration have been recommended for students who demonstrate a moderate or high level of STEM literacy. Furthermore, it has been theoretically justified that problem-based learning is the teaching method that would best fit these ways of integrating the STEM domains.

In relation to the foregoing, we must consider that when implementing the STEM approach it is not sufficient for the different disciplines to concur in the same project or problem situation if they do so from their perspective and curricular area. The contribution of different perspectives acquires its real meaning when the different disciplines interact, in a way that the understanding of the problem occurs within the sphere within which these visions cross paths. Therefore, the possibility of teacher training programs taking into consideration the figure of the STEM educator should not be a utopia. The profile of this person would be generalist, capable of knowing the basic premises and languages of the different disciplines and finding the nodes on which to make the different contributions pivot.

Lastly, from the review carried out in this essay, it has also been possible for us to detect some deficiencies which, in our view, should be the object of future research:

- Developing a valid and trustworthy instrument for evaluating STEM literacy in students.

- Empirically verifying, preferably with experimental or quasi-experimental designs, which level of integration disciplinary (nested, multidisciplinary, interdisciplinary, or transdisciplinary) and teaching method is capable of most successfully promoting STEM literacy.

Author Contributions: These authors contributed equally to this work. All authors have read and agreed to the published version of the manuscript.

Funding: The research is supported by Ministry of Science, Innovation and Universities (Spain) who finances the research project PGC2018-095765-B-I00 (PROFESTEM).

Institutional Review Board Statement: Not applicable.

Informed Consent Statement: Not applicable.

Data Availability Statement: Data is contained within the article.

Acknowledgments: To the University of Granada for the funding of the bridging grant-contract awarded to David Aguilera to complete his post-doctoral training. Further, to the Ministry of Science, Innovation and Universities for funding project PGC2018-095765-B-I00 (PROFESTEM) and to the Scientific Unit for Excellence in Teacher Training and Professional Development.

Conflicts of Interest: The authors declare no conflict of interest.

\section{References}

1. Breiner, J.M.; Harkness, S.S.; Johnson, C.C.; Koehler, C.M. What is STEM? A Discussion About Conceptions of STEM in Education and Partnerships. Sch. Sci. Math. 2012, 112, 3-11. [CrossRef]

2. Bybee, R.W. The Case for STEM Education: Challenges and Opportunities; NSTA Press: Arlington, VA, USA, 2013. 
3. Martín-Páez, T.; Aguilera, D.; Perales-Palacios, F.J.; Vílchez-González, J.M. What are we talking about when we talk about STEM education? A review of literature. Sci. Educ. 2019, 103, 799-822. [CrossRef]

4. Dare, E.A.; Ring-Whalen, E.A.; Roehrig, G.H. Creating a continuum of STEM models: Exploring how K-12 science teachers conceptualize STEM education. Int. J. Sci. Educ. 2019, 41, 1701-1720. [CrossRef]

5. Ring, E.A.; Dare, E.A.; Crotty, E.A.; Roehrig, G.H. The Evolution of Teacher Conceptions of STEM Education Throughout an Intensive Professional Development Experience. J. Sci. Teach. Educ. 2017, 28, 444-467. [CrossRef]

6. Akerson, V.L.; Burgess, A.; Gerber, A.; Guo, M.; Khan, T.A.; Newman, S. Disentangling the Meaning of STEM: Implications for Science Education and Science Teacher Education. J. Sci. Teach. Educ. 2018, 29, 1-8. [CrossRef]

7. Ortiz-Revilla, J.; Adúriz-Bravo, A.; Greca, I.M. A Framework for Epistemological Discussion on Integrated STEM Education. Sci. Educ. 2020, 29, 857-880. [CrossRef]

8. Falloon, G.; Hatzigianni, M.; Bower, M.; Forbes, A.; Stevenson, M. Understanding K-12 STEM Education: A Framework for Developing STEM Literacy. J. Sci. Educ. Technol. 2020, 29, 369-385. [CrossRef]

9. Hsu, Y.-S.; Fang, S.-C. Opportunities and Challenges of STEM Education. In Asia-Pacific STEM Teaching Practices; Springer International Publishing: Berlin/Heidelberg, Germany, 2019; pp. 1-16.

10. Sanders, M.E. STEM, STEM education, STEM mania. Technol. Teach. 2008, 68, 20-26.

11. Thibaut, L.; Ceuppens, S.; De Loof, H.; De Meester, J.; Goovaerts, L.; Struyf, A.; Pauw, J.B.-D.; Dehaene, W.; Deprez, J.; De Cock, M.; et al. Integrated STEM Education: A Systematic Review of Instructional Practices in Secondary Education. Eur. J. STEM Educ. 2018, 3, 1-12. [CrossRef]

12. Wells, J.G. Integrative STEM education at Virginia Tech: Graduate preparation for tomorrow's leaders. Technol. Eng. Teach. 2013, 72, 28-35.

13. Palacios, F.J.P.; Aguilera, D. Ciencia-Tecnología-Sociedad vs. STEM: ¿Evolución, revolución o disyunción? Ápice. Rev. Educ. Científica 2020, 4, 1-15. [CrossRef]

14. Honey, M.; Pearson, G.; Schweingruber, H. (Eds.) STEM Integration in K-12 Education: Status, Prospects, and an Agenda for Research; National Academies Press: Cambridge, MA, USA, 2014.

15. Gresnigt, R.; Taconis, R.; Van Keulen, H.; Gravemeijer, K.; Baartman, L. Promoting science and technology in primary education: A review of integrated curricula. Stud. Sci. Educ. 2014, 50, 47-84. [CrossRef]

16. Chu, H.-E.; Martin, S.N.; Park, J. A Theoretical Framework for Developing an Intercultural STEAM Program for Australian and Korean Students to Enhance Science Teaching and Learning. Int. J. Sci. Math. Educ. 2019, 17, 1251-1266. [CrossRef]

17. Kim, P.W. The Wheel Model of STEAM Education Based on Traditional Korean Scientific Contents. Eurasia J. Math. Sci. Technol. Educ. 2016, 12, 2353-2371. [CrossRef]

18. Basham, J.D.; Israel, M.; Maynard, K. An Ecological Model of STEM Education: Operationalizing STEM for All. J. Spéc. Educ. Technol. 2010, 25, 9-19. [CrossRef]

19. Lou, S.-J.; Tsai, H.-Y.; Chung, C.-C. Construction and Development of iSTEM Learning Model. Eurasia J. Math. Sci. Technol. Educ. 2017, 14, 15-32. [CrossRef]

20. Quigley, C.F.; Herro, D.; Jamil, F.M. Developing a Conceptual Model of STEAM Teaching Practices. Sch. Sci. Math. 2017, 117, 1-12. [CrossRef]

21. Kelley, T.R.; Knowles, J.G. A conceptual framework for integrated STEM education. Int. J. STEM Educ. 2016, 3, 1. [CrossRef]

22. Pearson, G. National academies piece on integrated STEM. J. Educ. Res. 2017, 110, 224-226. [CrossRef]

23. Sanders, M.E. Integrative STEM education as best practice. In Explorations of Best Practice in Technology, Design, E Engineering Education; Griffith Institute for Educational Research: Queensland, Australia, 2012.

24. Washington STEM Study Group. What Is STEM literacy? Available online: http://www.k12.wa.us/STEM/default.aspx\#2 (accessed on 14 January 2020).

25. Bybee, R.W. Advancing STEM education: A 2020 vision. Technol. Eng. Teach. 2010, 70, 30-35.

26. Linn, M.C.; Davis, E.A.; Bell, P. Internet Environments for Science Education; Lawrence Erlbraum Associates: Mahwah, NJ, USA, 2004.

27. Crawford, B.A. Learning to teach science as inquiry in the rough and tumble of practice. J. Res. Sci. Teach. 2007, 44, 613-642. [CrossRef]

28. Toma, R.B.; Greca, I.M. The Effect of Integrative STEM Instruction on Elementary Students' Attitudes toward Science. Eurasia J. Math. Sci. Technol. Educ. 2018, 14, 1383-1395. [CrossRef]

29. Boud, D. The Challenge of Problem-based Learning. Chall. Probl. Based Learn. 2013. [CrossRef]

30. Savin-Baden, M. Challenging models and perspectives of problem-based learning. In Management of Change. Implementation of Problem-Based and Project-Based Learning in Engineering; de Graaff, E., Kolmos, A., Eds.; Sense Publishers: Berlin/Heidelberg, Germany, 2007; pp. 9-29.

31. Chung, C.-C.; Lou, S.-J.; Chou, Y.-C.; Shih, R.-C. A Study of Creativity in CaC2 Steamship-derived STEM Project-based Learning. Eurasia J. Math. Sci. Technol. Educ. 2017, 13, 2387-2404. [CrossRef]

32. Chae, D.-H.; Kim, H. The Development and Application of a STEAM Program Based on Traditional Korean Culture. Eurasia J. Math. Sci. Technol. Educ. 2016, 12, 1925-1936. [CrossRef]

33. Grubbs, M.; Strimel, G. Engineering Design: The Great Integrator. J. STEM Teach. Educ. 2015, 50, 8. [CrossRef]

34. Friesen, M.; Taylor, K.L.; Britton, M.R. A Qualitative Study of a Course Trilogy in Biosystems Engineering Design. J. Eng. Educ. 2005, 94, 287-296. [CrossRef] 
35. Shahali, E.H.M.; Halim, L.; Rasul, M.S.; Osman, K.; Zulkifeli, M.A. STEM Learning through Engineering Design: Impact on Middle Secondary Students' Interest towards STEM. Eurasia J. Math. Sci. Technol. Educ. 2016, 13, 1189-1211. [CrossRef]

36. Carter, M. Problem Solving Reconsidered: A Pluralistic Theory of Problems. Coll. Engl. 1988, 50, 551. [CrossRef]

37. Ausubel, D.P. Educational Psychology: A Cognitive View; Holt, Rinehart \& Winston: New York, NY, USA, 1968.

38. Gallagher, S.A. Problem-Based Learning: Where Did it Come from, What Does it Do, and Where is it Going? J. Educ. Gift. 1997, 20, 332-362. [CrossRef]

39. Wiggins, G. The futility of trying to teach everything of importance. Educ. Leadersh. 1989, 47, 44-59.

40. Minstrell, J. Teaching science for understanding. In Toward the Thinking Curriculum; Resnick, L.B., Klopfer, L.E., Eds.; Asso-ciation for Supervision and Curriculum Development: New York, NY, USA, 1989; pp. 129-149.

41. Tekkumru-Kisa, M.; Stein, M.K.; Doyle, W. Theory and Research on Tasks Revisited: Task as a Context for Students' Thinking in the Era of Ambitious Reforms in Mathematics and Science. Educ. Res. 2020, 49, 606-617. [CrossRef] 